\title{
Mental Logic and the Denials of Conjunctions And Disjunctions ${ }^{1}$
}

\author{
Miguel López-Astorga ${ }^{2}$
}

\begin{abstract}
The mental models theory predicts that, while conjunctions are easier than disjunctions for individuals, when denied, conjunctions are harder than disjunctions. Khemlani, Orenes, and Johnson-Laird proved that this prediction is correct in their work of 2014. In this paper, I analyze their results in order to check whether or not they really affect the mental logic theory. My conclusion is that, although Khemlani et al.'s study provides important findings, such findings do not necessarily lead to questioning or to rejecting the mental logic theory.
\end{abstract}

KEYWORDS: conjunction; denial; disjunction; mental logic; mental models.

\section{INTRODUCTION}

At present, there are several interesting theories in cognitive science field trying to explain human inferential processes. Two of them are especially relevant: the mental models theory (BYRNE; JOHNSON-LAIRD, 2009; JOHNSON-LAIRD, 2010, 2012; JOHNSON-LAIRD: BYRNE; GIROTTO, 2009; KHEMLANI; JOHNSON-LAIRD, 2009; KHEMLANI; ORENES; JOHNSON-LAIRD, 2012, 2014; ORENES; JOHNSONLAIRD, 2012) and the mental logic theory (BRAINE; O'BRIEN, 1998a; O'BRIEN, 2009; O'BRIEN; MANFRINATI, 2010). The mental models theory (from now on, MM) states, as it is well known, that human reasoning is not a syntactic process, but a semantic process, and that, therefore, logical forms are not relevant for it. According to the proponents of MM, human beings' thinking works analyzing the possibilities that can be linked to sentences or assertions and selecting the possibilities that are compatible and that do not lead to inconsistencies.

\footnotetext{
${ }^{1}$ http://dx.doi.org/10.1590/S0101-31732016000100007

${ }^{2}$ Ph.D. in Logic and Philosophy of Science. Institute of Humanistic Studies "Juan Ignacio Molina", Talca University (Chile). Correspondence address: Miguel López-Astorga. Instituto de Estudios Humanísticos "Juan Ignacio Molina", Universidad de Talca. Av. Lircay s/n, Talca (Chile). Telephone number: (56-71) 2201603. E-mail: milopez@utalca.cl
} 
On the other hand, the mental logic theory (from now on, ML) is a syntactic approach, and hence logical rules and forms are very important for it. The problem of this theory is that it is often confused with other syntactic frameworks. In this way, it always seems opportune to highlight that, although $\mathrm{ML}$ is a syntactic theory, it does not claim that human mind follows the rules and the requirements of classical logic or systems such as that of Gentzen (1934). Likewise, it is also different to other syntactic approaches trying to describe the formal rules that people use when they reason, such as, for example, that of Rips (1994). ML is a theory with strong empirical support because it only admits the logical rules that, according to experimental results, individuals actually use.

Thus, it is evident that, if we want to know which one of these two theories is a better alternative, we need to identify particular cognitive tasks for which the predictions of both theories are not the same. Khemlani, Orenes and Johnson-Laird (2014) present a study of the denials of the connectives 'and', 'if...then', and 'or', and, in principle, it appears that their results can only be clearly explained by MM. In fact, MM predicts such results. Therefore, it could be thought that Khemlani, Orenes and Johnson-Laird (2014) research can be considered to be a proof that the theses of MM provide a more accurate description of human reasoning.

However, I think that Khemlani, Orenes and Johnson-Laird (2014) results are also consistent with the theses of ML. In my view, the predictions of ML about the tasks included in Khemlani, Orenes and Johnson-Laird (2014) study are not very different to those of MM, and, therefore, such tasks cannot prove which one of the two theories is more appropriate. To show that is the main aim of this paper. Nevertheless, I will only address the cases of conjunctions and disjunctions. Conditionals will be ignored because they are so complex that they deserve separate consideration.

In this way, my goal is not to demonstrate that Khemlani, Orenes and Johnson-Laird (2014) results can be explained by any syntactic approach. As it can be checked below, those results do not seem absolutely compatible with a framework claiming, for example, that human mind works following the formal rules of standard propositional calculus. And, as argued by Khemlani, Orenes and Johnson-Laird (2014), theories such as that of Rips (1994) cannot also account for their results. As said, I will only try to show that such results are also consistent with just ML. To do this, I will begin by commenting in more details the general theses of both MM and ML. Then I will describe 
what the part of Khemlani, Orenes and Johnson-Laird (2014) research about conjunctions and disjunctions really consisted of. Finally, I will argue in favor of the idea that ML can also explain all Khemlani, Orenes and Johnson-Laird (2014) results related to conjunctions, disjunctions, and their negations.

\section{AND THE ANALYSIS OF THE POSSIBILITIES CORRESPONDING TO CONJUNCTION AND DISJUNCTION}

As indicated, MM states that human mind works considering the possibilities to which propositions refer. Nonetheless, the theory does not attribute the same possibilities to the different logical operators. In addition, it claims that individuals do not identify all the possibilities or models corresponding to propositions in every case. However, for the purposes of this paper, I will only consider ideal situations in which people are able to detect all the models of the propositions (in MM terminology, the 'fully explicit models') including conjunctions or disjunctions.

It seems that, in principle, according to MM, the models that can be linked to propositions are those that coincide with the cases in which they are true in a truth table of classical logic. Thus, a conjunction, i.e., a proposition such as 'p and q', has only one model:

$\mathrm{p} \quad \mathrm{q}$

The model represents a situation in which both $\mathrm{p}$ and $\mathrm{q}$ are true, that is, the only situation in which, following the truth table of conjunction, a conjunction is true. As it is well known, $v(\mathrm{p} \cdot \mathrm{q})=1$ if, and only if, $v(\mathrm{p})=1$ and $v(\mathrm{q})=1$

Where ' $v$ ' refers to the truth value of the formula between brackets, '.' stands for conjunction, and ' 1 ' means 'true'.

And

$\mathrm{v}(\mathrm{p} \cdot \mathrm{q})=0$ in the other three cases, i.e., in these cases:

-When $\mathrm{v}(\mathrm{p})=1$ and $\mathrm{v}(\mathrm{q})=0$

-When $\mathrm{v}(\mathrm{p})=0$ and $\mathrm{v}(\mathrm{q})=1$

-When $\mathrm{v}(\mathrm{p})=0$ and $\mathrm{v}(\mathrm{q})=0$

Where ' 0 ' is 'false'. 
As far as disjunction is concerned, it is necessary to distinguish between inclusive and exclusive disjunction. The fully explicit models of inclusive disjunctions are as follows:

$\mathrm{p} \quad \mathrm{q}$

$\neg \mathrm{p} \quad \mathrm{q}$

$\mathrm{p} \neg \mathrm{q}$

Where ' $\neg$ ' denotes denial.

Again, these models correspond to the cases in which inclusive disjunction is true in its truth table because

$v(\mathrm{p} \mathrm{q})=1$ if, and only if, $v(\mathrm{p})=1$ or $v(\mathrm{q})=1$, i.e., in these three cases:

-When $v(\mathrm{p})=1$ and $v(\mathrm{q})=1$

-When $v(\mathrm{p})=0$ and $v(\mathrm{q})=1$

-When $v(\mathrm{p})=1$ and $v(\mathrm{q})=0$

Where 'v' stands for inclusive disjunction.

Therefore,

$v(\mathrm{p} \vee \mathrm{q})=0$ if, and only if, $v(\mathrm{p})=0$ and $v(\mathrm{q})=0$

But, if the disjunction is exclusive, the first model (i.e., that in which both $\mathrm{p}$ and $\mathrm{q}$ are true) is not accepted. Thus, its models are:

$\mathrm{p} \neg \mathrm{q}$

$\neg \mathrm{p} \quad \mathrm{q}$

This is because

$v(\mathrm{p} \underline{\mathrm{v}} \mathrm{q})=1$ only in two cases:

-When $v(\mathrm{p})=1$ and $v(\mathrm{q})=0$

-When $v(\mathrm{p})=0$ and $v(\mathrm{q})=1$

Where ' $\underline{\text { ' }}$ represents exclusive disjunction.

And

$v(\mathrm{p} \underline{\mathrm{v}} \mathrm{q})=0$ in the other two cases:

-When $v(\mathrm{p})=1$ and $v(\mathrm{q})=1$

-When $v(\mathrm{p})=0$ and $v(\mathrm{q})=0$

Nevertheless, in spite of the mentioned coincidences, MM does not claim that human reasoning is based on the truth tables of classical logic. The models of a particular proposition can be modulated because of its semantic meaning or pragmatic factors. But, given that I am only considering ideal situations, what is important here is that Khemlani, Orenes and JohnsonLaird (2012) studied which the models of denied propositions could be. 
Their proposal is that, if we want to identify the models that can be linked to a denied proposition, we only need to consider the complement of the models of that proposition without denial. This means that the models of a proposition such as $\neg(\mathrm{p} \cdot \mathrm{q})$ are the complement of the model of $\mathrm{p} \cdot \mathrm{q}$, that is,

$\mathrm{p} \neg \mathrm{q}$

$\neg \mathrm{p} \quad \mathrm{q}$

$\neg \mathrm{p} \neg \mathrm{q}$

It can be interesting to think about truth tables again, since it can be said that these last models are also the situations in which $\neg(\mathrm{p} \cdot \mathrm{q})$ is true in its truth table. Indeed,

$v[\neg(\mathrm{p} \cdot \mathrm{q})]=1$ if, and only if, $v(\mathrm{p} \cdot \mathrm{q})=0$

Likewise, the complement of the models of inclusive disjunction consists of only one model:

$\neg \mathrm{p} \neg \mathrm{q}$

This is hence the model of $\neg(\mathrm{p} \vee \mathrm{q})$ and, as it is also well known,

$v[\neg(\mathrm{p} \vee \mathrm{q})]=1$ if, and only if, $v(\mathrm{p} \vee \mathrm{q})=0$

In the same way, the models corresponding to $\neg(\mathrm{p} \underline{\mathrm{v}} \mathrm{q})$ are the complement of the models corresponding to $\mathrm{p} \underline{\mathrm{v}} \mathrm{q}$, that is,

$\mathrm{p} \quad \mathrm{q}$

$\neg \mathrm{p} \neg \mathrm{q}$

The correspondence with the truth tables is evident here as well, since $v[\neg(\mathrm{p} \underline{\mathrm{q}})]=1$ if, and only if, $v(\mathrm{p} \underline{\mathrm{v}} \mathrm{q})=0$

Maybe it can be opportune to indicate that the proponents of MM do not generally resort to truth tables for exposing their theses. As said, MM does not state that human beings reason by means of truth tables. However, I have referred to them here in order to show that semantics is very relevant in this theory and which, in my view, the links between it and logic are. In any case, aside from many papers authored by the proponents of MM, an exposition akin to the previous one without references to truth tables can be found, for example, in López-Astorga (2014). On the other hand, as far as the goal of this paper is concerned, there are two more points of MM that need to be taken into account. Firstly, according to it, the more models an inference requires, the more complex that inference will be. This means, for example, that inferences involving a conjunction (which only requires one model) 
will be usually easier than inferences involving a disjunction (which requires three models if it is inclusive and two models if it is exclusive). Secondly, other important prediction of MM is that, while individuals tend to interpret affirmative disjunctions as exclusive, denied disjunctions are often considered to be inclusive.

\section{AND ITS FORMAL RULES}

The framework proposed by ML is quite different. This theory states that human reasoning works following formal rules, but, as mentioned, not all the rules of standard propositional calculus. A very representative case can be that of the disjunction introduction rule, i.e.,

$\mathrm{p} / /$ Ergo p v q

This rule is absolutely correct in standard propositional calculus. Nevertheless, ML does not admit it because empirical evidence suggests that people do not often use it. Thus, this theory only accepts the rules that have experimental support. Between them, the proponents of ML distinguish several types:

-'Core Schemata': the schemata that people apply in all the occasions in which it is possible to do it. An example of this kind of rule related to conjunction is this one:

$\neg\left(\mathrm{p}_{1} \cdot \ldots \cdot \mathrm{p}_{\mathrm{n}}\right) ; \mathrm{p}_{\mathrm{i}} / / \operatorname{Ergo} \neg\left(\mathrm{p}_{1} \cdot \ldots \cdot \mathrm{p}_{\mathrm{i}-1} \cdot \mathrm{p}_{\mathrm{i}+1} \cdot \ldots \cdot \mathrm{p}_{\mathrm{n}}\right)$

With other symbols, this is schema 4 in Braine and O'Brien (1998b) and, as it is known, it is a version of an argument attributed to Chrysippus of Soli and the Stoic philosophy: modus ponendo tollens.

In this way, an example related to disjunction can be the following: $\mathrm{p}_{1} \mathrm{v} \ldots \mathrm{v} \mathrm{p}_{\mathrm{n}} ; \neg \mathrm{p}_{\mathrm{i}} / /$ Ergo $\mathrm{p}_{1} \mathrm{v} \ldots \mathrm{v} \mathrm{p}_{\mathrm{i}-1} \mathrm{v} \mathrm{p}_{\mathrm{i}+1} \mathrm{v} \ldots \mathrm{v} \mathrm{p}_{\mathrm{n}}$

With other symbols, this is schema 3 in Braine and O'Brien (1998b) and it can also be considered to be a version of other argument attributed to Chrysippus: modus tollendo ponens.

-'Feeder Schemata': these schemata are only applied when their use can allow drawing conclusions. A representative example of this type of schema can be as follows:

$\mathrm{p}_{1} ; \mathrm{p}_{2} ; \ldots ; \mathrm{p}_{\mathrm{n}} / /$ Ergo $\mathrm{p}_{1} \cdot \mathrm{p}_{2} \cdot \ldots \cdot \mathrm{p}_{\mathrm{n}}$ 
With other symbols, this is schema 8 in Braine and O'Brien (1998b). The cause why these schemata have a restriction and are not always applied is obvious. If they were used whenever possible, it would be possible to derive infinite conclusions, since any formula could be linked to any other formula infinite times by means of a conjunction.

-'Incompatibility schemata': they are the schemata that show that a contradiction has been found and that, therefore, at least one of the assumptions is false. An example is:

p; $\neg$ // Ergo INCOMPATIBLE

With other symbols, this is schema 10 in Braine and O'Brien (1998b).

-'Other Schemata': other schemata that people can use in certain cases. An example is this one:

$\mathrm{p} \cdot\left(\mathrm{q}_{1} \mathrm{v} \ldots \mathrm{v} \mathrm{q}_{\mathrm{n}}\right) / / \operatorname{Ergo}\left(\mathrm{p} \cdot \mathrm{q}_{1}\right) \mathrm{v} \ldots \mathrm{v}\left(\mathrm{p} \cdot \mathrm{q}_{\mathrm{n}}\right)$

With other symbols, this is schema 14 in Braine and O'Brien (1998b).

An important thesis of ML is that people apply schemata such as those corresponding to the mentioned examples when they understand that the expressions refer to certain logical operators. In this way, it is very relevant that words such as 'and', 'or', 'if'... appear in the expressions in natural language. Nonetheless, other essential thesis of this theory is that it proposes a program that describes the order in which the schemata can be used. Thus, it claims that there is a 'Direct Reasoning Routine' and 'Indirect Reasoning Strategies' (which are used when the Direct Reasoning Routine does not enable to evaluate a conclusion or to derive any conclusion). However, for the aim of this paper, it can be enough to comment that the Direct Reasoning Routine includes an 'Evaluation Procedure' and an 'Inference Procedure'.

The Evaluation Procedure is the procedure to be used to check whether a particular conclusion is true or false. This procedure only allows applying Feeder Schemata and its goal is to detect whether the premises lead us to the conclusion or, conversely, the conclusion is inconsistent with the premises. If this procedure does not provide results, individuals resort to the Inference Procedure, which enables to use Core Schemata as well. Nevertheless, the aim continues to be the same: to check whether the conclusion can be drawn from or is incompatible with the premises. 
The Direct Reasoning Routine hence is not a procedure to determine whether or not a particular proposition is possible. If that proposition is inconsistent with the premises, it can note that circumstance. Nonetheless, its main goal is not to indicate whether or not a proposition that cannot be inferred from the premises is possible. In my view, this is an important difference of perspective that will have to be taken into account in the discussion that I will raise below. However, other relevant datum can be that, according to ML, the use of Feeder Schemata is extremely easy (BRAINE et al., 1998). In fact, their application is so simple that people do not often realize that they have used them. In many cases, individuals think that, when they resort to a Feeder Schema, they are not really making an inference, but expressing the same content in a different way (as far as this matter is concerned, it can also be interesting, as mentioned by Braine et al., 1998, to pay attention to Fillenbaum's, 1977, work). As I will show below too, this point is also relevant for the problem that I am addressing in this paper.

\section{Khemlani, Orenes and Johnson-Laird (2014) eXPeriments}

Based on MM, Khemlani, Orenes and Johnson-Laird (2014) describe the predictions of this last theory on propositions with different forms, including $\mathrm{p} \cdot \mathrm{q}, \mathrm{p} \underline{\mathrm{v}} \mathrm{q}, \neg(\mathrm{p} \cdot \mathrm{q})$, and $\neg(\mathrm{p} \mathrm{v} \mathrm{q})$. Given that, as mentioned, $\mathrm{p}$. $\mathrm{q}$ has only one model and $\mathrm{p} \underline{\mathrm{v}} \mathrm{q}$ has two models, a first prediction is that the mental operations with $\mathrm{p} \underline{\mathrm{v}} \mathrm{q}$ will be harder than those with $\mathrm{p} \cdot \mathrm{q}$. Likewise, because, as also indicated, $\neg(\mathrm{p} \cdot \mathrm{q})$ refers to three models and $\neg(\mathrm{p} v \mathrm{q})$ refers only to one model, another prediction is that the inferences involving $\neg(\mathrm{p} \cdot \mathrm{q})$ will be more difficult than those involving $\neg(\mathrm{p} \vee \mathrm{q})$. To check such predictions (and others), they carry out a first experiment in which, in some conditions, they use sentences such as this one: "[A] "Bob [asserted/denied] that he wore a yellow shirt [and/or] he wore blue pants on Monday." (KHEMLANI; ORENES; JOHNSON-LAIRD, 2014, p.4).

Obviously, the first square brackets mean that, in some conditions, the word was 'asserted' and, in the other conditions, the word was 'denied'. Likewise, the second square brackets indicates that, in some conditions, the word was 'and' and, in the other conditions, the word was 'or'. Thus, it can be said that Khemlani, Orenes and Johnson-Laird. (2014) used sentences with the four structures mentioned above, i.e., $\mathrm{p} \cdot \mathrm{q}, \mathrm{p} \underline{\mathrm{v}} \mathrm{q}, \neg(\mathrm{p} \cdot \mathrm{q})$, and $\neg(\mathrm{p} \mathrm{v} \mathrm{q})$. Note that I am considering, as MM does, disjunction to be exclusive when 
the sentence is affirmative, and to be inclusive when the sentence is denied. In this way, participants' task was to indicate, in each of the mentioned cases, whether or not the following situations were possible:

Bob wore a yellow shirt and he wore blue pants.

Bob wore a yellow shirt and he wore non-blue pants.

Bob wore a non-yellow shirt and he wore blue pants.

Bob wore a non-yellow shirt and he wore non-blue pants. (KHEMLANI;

ORENES; JOHNSON-LAIRD, 2014, p.4).

As it can be noted, the formal structures of these propositions are:

$[B] \mathrm{p} \cdot \mathrm{q}$

$[\mathrm{C}] \mathrm{p} \cdot \neg \mathrm{q}$

$[\mathrm{D}] \neg \mathrm{p} \cdot \mathrm{q}$

$[\mathrm{E}] \neg \mathrm{p} \cdot \neg \mathrm{q}$

So, it is obvious that the possibilities that correspond to the different versions of $[\mathrm{A}]$ are these ones:

$\mathrm{p} \cdot \mathrm{q}:[\mathrm{B}]$

$\mathrm{p} \underline{\mathrm{v}} \mathrm{q}:[\mathrm{C}]$ and $[\mathrm{D}]$

$\neg(\mathrm{p} \cdot \mathrm{q}):[\mathrm{C}],[\mathrm{D}]$, and $[\mathrm{E}]$

$\neg(\mathrm{p} \vee \mathrm{q}):[\mathrm{E}]$

The results achieved by Khemlani, Orenes and Johnson-Laird (2014) seemed to support the predictions of MM, since participants made more errors in the case of $\mathrm{p} \underline{\mathrm{v}} \mathrm{q}$ than in that of $\mathrm{p} \cdot \mathrm{q}$, and in the case of $\neg(\mathrm{p} \cdot \mathrm{q})$ than in that of $\neg(p \vee q)$. And an interesting finding was that, in the case of $\neg(p \cdot q)$, participants appeared to tend to elect only $[\mathrm{E}]$ as a possible situation, and to consider [C] and, to a lesser extent, [D] to be impossible.

In a second experiment, participants had to deny assertions and the relevant results for this paper are that they seemed to note without difficulties that $\neg(\mathrm{p} \vee \mathrm{q})$ is equivalent to $\neg \mathrm{p} \cdot \neg \mathrm{q}$, and to misinterpret $\neg(\mathrm{p} \cdot \mathrm{q})$, since, apparently, they thought that this last formula was equivalent to $\neg p \cdot \neg q$ too.

It is true that the terms 'denial' and 'negation' does not mean exactly the same. Nonetheless, because Khemlani, Orenes and Johnson-Laird. (2014) decided to use them as if their meanings were identical, I do so as well. In any 
case, as said, my aim here is only to show that the mentioned results are also consistent with the main theses of ML. I will do that in the next sections.

\section{AND P $\cdot Q$}

As indicated, the ML program is not a program for determining whether or not a particular proposition is possible given certain premises. Of course, it can identify the propositions that are incompatible with the premises, However, as I understand it, if a proposition cannot be deduced from the premises, the program cannot indicate for sure whether that proposition is possible or not. Having said that, I will start by analyzing the case in which the structure of $[\mathrm{A}]$ is $\mathrm{p} \cdot \mathrm{q}$.

-Possibility [B]: in this condition, a reiteration is found: $\mathrm{p} \cdot \mathrm{q} / / \operatorname{Ergo} \mathrm{p} \cdot \mathrm{q}$

Therefore, it is evident why participants thought that, if the premise is $\mathrm{p} \cdot \mathrm{q},[\mathrm{B}]$ is possible.

-Possibility [C]: a simple use of a Feeder Schema allows detecting an inconsistency. Other Feeder Schema of ML is as follows:

$\mathrm{p}_{1} \cdot \ldots \cdot \mathrm{p}_{\mathrm{i}} \cdot \ldots \cdot \mathrm{p}_{\mathrm{n}} / /$ Ergo $\mathrm{p}_{\mathrm{i}}$

In particular, with other symbols, this is schema 9 in Braine and O'Brien (1998b). Well then, if this schema is taken into account, it is easy to understand why participants tended to respond that, given $\mathrm{p} \cdot \mathrm{q},[\mathrm{C}]$ is not possible.

-Possibility [D]: again, it is obvious that, if schema 9 is used, an incompatibility is found.

-Possibility [E]: as in the previous two cases, schema 9 reveals and inconsistency.

So, the reasons why Khemlani, Orenes and Johnson-Laird (2014) participants considered that, if $\mathrm{p} \cdot \mathrm{q}$ is taken as premise, only [B] is possible are absolutely clear. To note that, it is only necessary to use a Feeder Schema, schema 9, and, as said, Feeder Schemata are not hard to apply. Sometimes they are used unconsciously. However, what is most important is that, if only Feeder Schemata were applied, it can be said that individuals only followed the Evaluation Procedure, and that they did not need to resort to the Inference 
Procedure. It is hence evident, from the perspective of ML, why this task is so simple when $[\mathrm{A}]$ is equivalent to $\mathrm{p} \cdot \mathrm{q}$.

\section{AND P V Q}

But the situation is different when the formal structure of $[\mathrm{A}]$ is $\mathrm{p} \underline{\mathrm{v}} \mathrm{q}$. In this case, what happens to each possibility is as follows:

-Possibility [B]: it is obvious that $\mathrm{p} \underline{\mathrm{v}} \mathrm{q}$ can only be considered to be incompatible with [B] if that disjunction is interpreted, as MM claims, as exclusive, i.e., as ' $\underline{v}$ ', and not as ' $v$ '. Maybe this is an idea of MM that must be assumed for accounting for Khemlani et al.'s (2014) results from the framework of ML. Nevertheless, I think that it is not necessary to accept, as MM does, that affirmative disjunctions are always exclusive. According to ML, pragmatics has an influence on reasoning (BRAINE; O'BRIEN, 1998c) and it can be thought that pragmatics is precisely the factor that indicates whether a particular disjunction is exclusive or inclusive. Thus, it can be accepted that the affirmative disjunctions included in Khemlani, Orenes and Johnson-Laird (2014) experiments are usually interpreted as exclusive without assuming that affirmative disjunctions are always interpreted as exclusive. Undoubtedly, this point requires further research in order to exactly determine when a disjunction is understood as exclusive and when it is understood as inclusive. In any case, if we suppose that the affirmative disjunctions proposed by Khemlani, Orenes and Johnson-Laird (2014) are exclusive, it is very easy for ML to explain why their participants thought that those disjunctions were inconsistent with [B]. As I understand it, in ML it is possible to transform disjunctions into clear exclusive disjunctions. This can be made in the same way as it is made in other syntactic frameworks. If $\neg(\mathrm{p} \cdot \mathrm{q})$ is added to $\mathrm{p} v \mathrm{q}, \mathrm{p} v \mathrm{q}$ is transformed into $\mathrm{p}$ $\underline{\mathrm{v}} \mathrm{q}$. If this is done, the deduction has two premises:

[1] p v q

[2] $\neg(\mathrm{p} \cdot \mathrm{q})$

Evidently, [B] is incompatible with [2] and, therefore, the reasons why Khemlani, Orenes and Johnson-Laird (2014) participants rejected [B] as a possibility when $[\mathrm{A}]$ was $\mathrm{p} \underline{\mathrm{v}} \mathrm{q}$ are clear too. 
-Possibility [C]: the problem here is that the use of Feeder Schemata is not enough to check whether $[\mathrm{C}]$ is incompatible with the premises or can be inferred from them. The best one can do is an inference such as this one:

[1] p v q (premise)

$[2] \neg(\mathrm{p} \cdot \mathrm{q})$ (premise)

[3] $\mathrm{p} \cdot \neg \mathrm{q}$ (assumption)

[4] p (schema 9; 3)

[5] ᄀq (schema 4; 2, 4)

[6] p (schema 3; 1, 5)

As it can be noted, in step [3], [C] is supposed in order to find a contradiction. Nonetheless, as it can also be seen, no inconsistency is found in the inference. It only reveals that $\mathrm{q}$ is not possible, that $\mathrm{p}$ leads to $\neg \mathrm{q}$, and that $\neg \mathrm{q}$ leads to $\mathrm{p}$. But two points are relevant here, which show why Khemlani, Orenes and Johnson-Laird (2014) task is more difficult when the structure of $[\mathrm{A}]$ is $\mathrm{p} \underline{\mathrm{v}} \mathrm{q}$ than when it is $\mathrm{p} \cdot \mathrm{q}$. Firstly, if schemata 3 and 4 are used, obviously, not only Feeder Schemata are applied (schemata 3 and 4 are Core Schemata). This can already explain why this experimental condition was harder for their participants (Feeder Schemata are easier to apply than Core Schemata). However, the use of Core Schemata implies in turn that their participants not only had to resort to the Evaluation Procedure, but also to the Inference Procedure. In addition, the previous inference does not really respond to the question of the task. The task asks individuals for answering whether or not $[\mathrm{C}]$ is possible, but, as mentioned, the Direct Reasoning Routine can only reveal whether a conclusion can be drawn from a set of premises or it is inconsistent with that set. It is evident that if, in principle, an incompatibility cannot be derived, although the conclusion cannot also be deduced from the premises, individuals can think that that conclusion is possible. Nevertheless, it is also clear that, in that case, more mental processing is needed and that there can always be certain levels of uncertainty. In my view, these are enough reasons to understand why Khemlani, Orenes and Johnson-Laird (2014) participants made more errors in this condition than in that in which the structure of $[\mathrm{A}]$ corresponded to $\mathrm{p} \cdot \mathrm{q}$.

-Possibility [D]: the arguments that can be given for this possibility are very similar to those offered for [C]. As it can be easily noted, a deduction akin to the previous one in which the assumption in step [3] were [D], and not [C], would reveal that $\mathrm{p}$ is not possible, that $\neg \mathrm{p}$ leads to $\mathrm{q}$, and that $\mathrm{q}$ leads to $\neg \mathrm{p}$. Therefore, Core Schemata would be needed again, and, likewise, the Inference 
Procedure would be necessary as well. In the same way, while a contradiction could not be derived, the Direct Reasoning Routine would not also allow inferring $[\mathrm{D}]$. So, there would be certain uncertainty as well.

-Possibility [E]: the case is very different here because $\mathrm{p} v \mathrm{q}$ and $\neg \mathrm{p} \cdot \neg \mathrm{q}$ cannot be true at the same time. Schema 3 forbids it. Nonetheless, although there is no uncertainty in this condition, schema 3 is a Core Schema, which is hence linked to the Inference Procedure, and, as said, that circumstance raises the level of difficulty.

For these reasons, it can be stated that ML also predicts that Khemlani et al.'s (2014) task is harder when [A] is $\mathrm{p} \underline{\mathrm{v}} \mathrm{q}$ than when it is $\mathrm{p} \cdot \mathrm{q}$. Thus, this fact does not lead one to question or reject ML.

ML AND $\neg(\mathrm{P} \cdot \mathrm{Q})$

A problematic case seems to be that in which $[\mathrm{A}]$ is equivalent to $\neg(\mathrm{p}$. q). In principle, following the previous arguments, it can be easily understood why this case is especially hard. Let us take the different possibilities into account:

-Possibility [B]: clearly, schema 10 reveals a contradiction between $\neg(\mathrm{p}$ - q) and $\mathrm{p} \cdot \mathrm{q}$. Therefore, possibility $[\mathrm{B}]$ cannot be accepted if the structure of $[\mathrm{A}]$ is $\neg(\mathrm{p} \cdot \mathrm{q})$.

-Possibility $[\mathrm{C}]$ : no contradiction can be found and it appears that it is only possible to do the following:

[1] $\neg(\mathrm{p} \cdot \mathrm{q})$ (premise)

[2] $\mathrm{p} \cdot \neg \mathrm{q}$ (assumption)

[3] p (schema 9; 2)

[4] ᄀq (schema 4; 1,3)

Really, this process seems unnecessary, since $\neg \mathrm{q}$ can be directly inferred from [2] by means of schema 9. Maybe what is important is that, although $\neg(\mathrm{p} \cdot \mathrm{q})$ is not inconsistent with $\mathrm{p} \cdot \neg \mathrm{q}, \mathrm{p} \cdot \neg \mathrm{q}$ cannot be derived from $\neg(\mathrm{p} \cdot \mathrm{q})$. Thus, as in some of the previous situations, this circumstance can explain the especial difficulty of this experimental condition. 
-Possibility [D]: the scenario is very similar to that of possibility [C]. $\neg \mathrm{p} \cdot \mathrm{q}$ is not in contradiction with $\neg(\mathrm{p} \cdot \mathrm{q})$. However, it cannot also be drawn from $\neg(\mathrm{p} \cdot \mathrm{q})$.

-Possibility [E]: the situation continues to be very akin. $\neg(\mathrm{p} \cdot \mathrm{q})$ does not enable to derive $\neg \mathrm{p} \cdot \neg \mathrm{q}$. Nevertheless, both formulae are not inconsistent.

In my view, these arguments can explain why the case of $\neg(\mathrm{p} \cdot \mathrm{q})$ is more difficult than that of $\neg(\mathrm{p} v \mathrm{q})$, which will be addressed in the next section. Nonetheless, as mentioned, Khemlani, Orenes and Johnson-Laird (2014) found a tendency in this experimental condition. They noted that their participants tended to respond that the only possibility compatible with $\neg$ (p . q) was [E], and this fact can require an account too.

I think that a possible account is not hard to offer. It can be proposed that individuals do not deny $\mathrm{p} \cdot \mathrm{q}$ as $\neg(\mathrm{p} \cdot \mathrm{q})$, but as $\neg \mathrm{p} \cdot \neg \mathrm{q}$. There is evidence for assuming that. As far as I know, no formal theory claims that there is an exact and verbatim correspondence between expressions in natural language and their logical forms. In this way, it can be said that ML does not require or hold that correspondence. In fact, cognitive science literature reveals us some cases in which the denial of logical form is problematic. For example, if we assume that ' $\rightarrow$ ' stands for conditional relationship, it is not clear how individuals deny an expression such as $\mathrm{p} \rightarrow \mathrm{q}$. Sometimes they appear to deny it as $\neg(\mathrm{p} \rightarrow \mathrm{q})$, but other times they seem to deny it as $\mathrm{p} \rightarrow \neg \mathrm{q}$. This problem has been studied in many works and papers (HANDLEY; EVANS; THOMPSON, 2006; BYRNE; JOHNSON-LAIRD, 2009). Even Khemlani, Orenes and Johnson-Laird (2014) analyzes it as well. Therefore, it would not be surprising that individuals tended to deny $\mathrm{p} \cdot \mathrm{q}$ as $\neg \mathrm{p} \cdot \neg \mathrm{q}$.

Khemlani, Orenes and Johnson-Laird (2014) also appear to think about this last possibility, but they seem to take into account only the words used in their participants' answers in their second experiment. Nonetheless, the idea is that individuals can express a logical relation with different words in natural language, and these words can suggest that their mental representation of that relation is not the representation that they truly have. It hence can be more opportune to pay attention to the conclusions that people infer than to the words that they use. If we do that, it seems to be justified to think that Khemlani, Orenes and Johnson-Laird (2014) participants did not attribute the form $\neg(\mathrm{p} \cdot \mathrm{q})$ to $[\mathrm{A}]$ in this condition, but the form $\neg \mathrm{p} \cdot \neg \mathrm{q}$. This is because their more frequent responses are compatible with this last form. The reason 
is obvious: schema 9 shows that $\neg \mathrm{p} \cdot \neg \mathrm{q}$ is inconsistent with [B], [C], and [D], and that $[\mathrm{E}]$ is simply a reiteration of it.

But it can be argued against this that, according to ML, people can understand propositions such as $\neg(\mathrm{p} \cdot \mathrm{q})$ and that, therefore, they do not always deny $\mathrm{p} \cdot \mathrm{q}$ as $\neg \mathrm{p} \cdot \neg \mathrm{q}$. The key of this objection can be schema 4 , since that schema suggests that individuals can think that the denial of $\mathrm{p} \cdot \mathrm{q}$ is really $\neg(\mathrm{p} \cdot \mathrm{q})$. However, in my view, the most important point here is pragmatics again. Schema 4 is only used in contexts in which not only the first premise is, for example, $\neg(p \cdot q)$, but in which also the second premise is, for example, $p$, which clearly shows that the meaning of $\neg(\mathrm{p} \cdot \mathrm{q})$ is not $\neg \mathrm{p} \cdot \neg \mathrm{q}$.

In any case, we have two alternatives. On the one hand, it can be thought that the real logical form of $[\mathrm{A}]$ is $\neg(\mathrm{p} \cdot \mathrm{q})$. In this case, it can be said that the task is more difficult than other experimental conditions. On the other hand, we can accept that the form is actually $\neg$ p . $\neg$ q. Thus, the task can be considered to be a simple task in which the expected result is the result really achieved: the only possibility compatible with $[\mathrm{A}]$ is $[\mathrm{E}]$. What is interesting is that either of these is both consistent with ML and with the results obtained by Khemlani, Orenes and Johnson-Laird (2014).

\section{AND $\neg(P \vee Q)$}

Finally, if the structure of $[\mathrm{A}]$ is $\neg(\mathrm{p} \vee \mathrm{q})$, the explanation is easy. ML has several schemata involving disjunction that can lead one to think that, when individuals reason about disjunctions, they consider the possibilities linked to each disjunct. Such schemata are, in addition to the mentioned schemata 3 and 14, the following:

$\left(\mathrm{p}_{1} \mathrm{v} \ldots \mathrm{v} \mathrm{p}_{\mathrm{n}}\right) \rightarrow \mathrm{q} ; \mathrm{p}_{\mathrm{i}} / /$ Ergo q (with other symbols, schema 2 in Braine and O’Brien, 1998b)

$\mathrm{p}_{1} \mathrm{v} \ldots \mathrm{v} \mathrm{p}_{\mathrm{n}} ; \mathrm{p}_{1} \rightarrow \mathrm{q} ; \ldots ; \mathrm{p}_{\mathrm{n}} \rightarrow \mathrm{q} / /$ Ergo $\mathrm{q}$ (with other symbols, schema 5 in Braine and O’Brien, 1998b)

$\mathrm{p}_{1} \mathrm{v} \ldots \mathrm{v} \mathrm{p}_{\mathrm{n}} ; \mathrm{p}_{1} \rightarrow \mathrm{q}_{1} ; \ldots ; \mathrm{p}_{\mathrm{n}} \rightarrow \mathrm{q}_{\mathrm{n}} / /$ Ergo $\mathrm{q}_{1} \mathrm{v} \ldots \mathrm{v} \mathrm{q}_{\mathrm{n}}$ (with other symbols, schema 6 in Braine and O'Brien, 1998b)

$\mathrm{p}_{1} \mathrm{v} \ldots \mathrm{v} \mathrm{p}_{\mathrm{n}} ; \neg \mathrm{p}_{1} \cdot \ldots . \cdot \neg \mathrm{p}_{\mathrm{n}} / /$ Ergo INCOMPATIBLE (with other symbols, schema 11 in Braine and O'Brien, 1998b)

Thus, given that ML admits these schemata, one might think that, according to ML, people clearly know that a particular disjunction is true if just one of its disjuncts is true, and that, therefore, that $\neg(\mathrm{p} v \mathrm{q})$ means that 
none of the two disjuncts is true. So, it is evident that the prediction of ML can be that, if [A] is equivalent to $\neg(\mathrm{p} \vee \mathrm{q})$, individuals tend to reject [B] (the two disjuncts are true), $[\mathrm{C}]$ ( $\mathrm{p}$ is true), and [D] (q is true). Likewise, they tend to accept $[\mathrm{E}]$, since it fulfills the requirement that the two disjuncts are false.

An interesting study in this regard is that of Macbeth et al. (2014). Adopting MM, they try to prove that one of DeMorgan's (1847) laws is easier that the other one for reasoners. As it is well known, DeMorgan's laws are two:

$\neg(\mathrm{p} \cdot \mathrm{q}) / /$ Ergo $\neg \mathrm{p} v \neg \mathrm{q}$

$\neg(\mathrm{p} \vee \mathrm{q}) / / \operatorname{Ergo} \neg \mathrm{p} \cdot \neg \mathrm{q}$

Obviously, Macbeth et al.'s (2014) argument is that, because the first one refers to three models and the second one refers to only one model, people infer $\neg p \cdot \neg q$ from $\neg(\mathrm{p} v \mathrm{q})$ more often than they derive $\neg \mathrm{p} v \neg \mathrm{q}$ from $\neg(\mathrm{p}$. q). Their experimental results seemed to demonstrate this idea and, for this reason, López-Astorga (2014) proposes, as a possibility, an extension of ML including the second law as a schema.

However, regardless of the fact that Macbeth et al.'s (2014) research has certain limitations that they recognize, López-Astorga (2014) also consider, and would have to be taken into account before accepting the mentioned extension of ML, one might think that that extension is not needed. It is evident that, as said, many schemata of ML involve disjunction. For this reason, it can be thought that this theory claims that individuals perfectly know the nature of disjunction and that they can realize that $\neg(\mathrm{p} v \mathrm{q})$ leads to $\neg \mathrm{p} \cdot \neg \mathrm{q}$.

In any case, what appears to be important is that ML can explain Khemlani et al.'s (2014) results as well. In the case of denials, it can be stated that the possibilities corresponding to $\neg(\mathrm{p} \vee \mathrm{q})$ are easier to be identified than those of $\neg(\mathrm{p} \cdot \mathrm{q})$ because, when [A] is equivalent to $\neg(\mathrm{p} \cdot \mathrm{q})$, there is uncertainty with respect to some possibilities. Nonetheless, as indicated, it is also possible that individuals tend to think that the denial of $\mathrm{p} \cdot \mathrm{q}$ is not $\neg$ ( $\mathrm{p}$. $\mathrm{q}$ ), but $\neg \mathrm{p} \cdot \neg \mathrm{q}$. If this so, it can be said that the denial of disjunction and that of conjunction have a similar level of difficulty and that people often deny conjunctions and disjunctions in the same way. 


\section{ConClusions}

As mentioned, Khemlani, Orenes and Johnson-Laird (2014) study is broader, since they also consider conditional. Nevertheless, what is relevant for the aim of this paper is that, undoubtedly, their results are consistent with the theses of MM, lead to reject frameworks such as that of Rips (1994), and do not enable to think that human mind works following systems such as standard propositional calculus. I have not tried to prove otherwise. My only goal has been to show that such results are compatible with ML as well.

Nonetheless, Khemlani, Orenes and Johnson-Laird (2014) paper also provides us other interesting findings. Firstly, it seems that people consider affirmative disjunctions to be exclusive more times than is evident. This is, of course, an old problem, and, as O'Toole and Jennings (2004) remind us, was an important worry for the Stoics. Ancient sources (almost of them are mentioned by O'TOOLE; JENNINGS, 2004) confirm this point (for example, Cicero in Topica, Gellius in Noctes Atticae, Galen in Institutio Logica, or Sextus Empiricus in Outlines of Pyrrhonism) and it is clear that it is worth continuing to analyze this matter.

Secondly, other relevant point to be taken into account is that we have many early indications that human being often deny conjunctions considering their logical form to be $\neg \mathrm{p}$. $\neg \mathrm{q}$. If this were really the case, an important finding of Khemlani, Orenes and Johnson-Laird (2014) research would be that conjunctions and disjunctions tend to be denied in the same way, i.e., as $\neg p \cdot \neg q$. In my view, this idea is correct and it is evident that it can have impact on the studies about the problem of natural language processing and recovery of logical forms. So, it is another aspect that should continue to be researched.

Thirdly, if the framework of ML is adopted, the results achieved by Khemlani, Orenes and Johnson-Laird. (2014) suggest that a possibility can be an extension of that logic including one of DeMorgan's laws, in particular, $\neg$ (p v q) // Ergo $\neg \mathrm{p} \cdot \neg \mathrm{q}$. As indicated, this is a possibility already proposed by López-Astorga (2014). However, it seems very obvious that, following ML, people can easily note the equivalence between $\neg(\mathrm{p} \vee \mathrm{q})$ and $\neg \mathrm{p} \cdot \neg \mathrm{q}$, and that an extension such as that mentioned would require detailed and rigorous experiments in which many variables would have to be controlled. In addition, other problem would be, as also stated by López-Astorga (2014), to decide what kind of schema (Core, Feeder...) this new schema would be. For these 
reasons, although possible, the extension does not appear to be necessary. In fact, it does not seem even advisable.

In any case, some aspects are absolutely clear. MM is not the only theory that can account for the different levels of difficulty that can be observed in the understanding processes of inferences with conjunctions and disjunctions, whether they are affirmative or denied. According to ML, the possibilities corresponding to an affirmative conjunction are easier to identify than those of an affirmative disjunction because, in the case of affirmative conjunction, it is only needed to use a Feeder Schema and, therefore, only the Evaluation Procedure is made. Nonetheless, if the affirmative proposition is disjunctive, it is necessary to apply Core Schemata and to resort to the Inference Procedure. In addition, the program does not offer absolute security that the proposition is consistent with the premise.

On the other hand, when the propositions are denied, it can be said that the case of disjunction is not hard to explain. Many schemata in ML include disjunctions and this fact can lead one to assume that people tend to interpret the disjunctive relationships correctly, which in turn allows understanding why denied disjunctions are often so easy for individuals. As far as denied conjunctions are concerned, as commented, two alternative explanations can be considered. It can be thought that people tend to attribute to them the logical form $\neg(\mathrm{p} \cdot \mathrm{q})$. In this case, there are possibilities that cannot be derived from the premise and uncertainty accounts for their level of difficulty. However, it can also be assumed that their actual logical form is $\neg p$ - $\neg \mathrm{q}$. If this is the case, denied conjunctions are as easy as denied disjunctions, since the adequate possibility can be detected easily in the two situations (in inferences in which the premise is a denied conjunction, it is enough to use a Feeder Schema). As said, we have early indications that the correct alternative is this last one.

\section{ACKNOWLEDGMENTS}

This paper is a partial result of the Project N. I003011, "Algoritmos adaptativos e inferencias lógicas con enunciados condicionales", supported by the Directorate for Research of Talca University (Dirección de Investigación de la Universidad de Talca), Chile. The author, who is also the main researcher of that Project, would like to thank the mentioned institutions for their help 
in funding this paper, and the anonymous experts that reviewed it for their comments, which, undoubtedly, improved the final text.

LÓPEZ-ASTORGA, Miguel. A lógica mental e as negaçóes das conjunçóes e disjunções. Trans/form/ação, Marília, v. 39, n. 1, p. 119-138, Jan./Mar., 2016.

RESUMO: A teoria dos modelos mentais prevê que, enquanto as conjunçôes são mais fáceis do que as disjunçôes, para os indivíduos, quando negadas, as conjunçôes sấo mais difíceis do que as disjunçóes. Khemlani, Orenes e Johnson-Laird provaram que essa previsão está correta, em seu trabalho de 2014. Neste trabalho, analiso os seus resultados, a fim de verificar se eles realmente afetam a teoria da lógica mental ou não. Minha conclusão é que, embora o estudo da Khemlani, Orenes and Johnson-Laird forneça resultados importantes, tais resultados não conduzem necessariamente a minar ou rejeitar a teoria da lógica mental.

PALAVRAS-CHAVE: Conjunção. Negação. Disjunção. Lógica mental. Modelos mentais.

\section{REFERENCES}

BRAINE, M. D. S.; O’BRIEN, D. P. Mental logic. Mahwah: Lawrence Erlbaum Associates, 1998a.

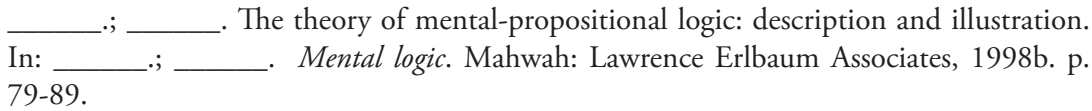

.; How to investigate mental logic and the syntax of thought. In: ; Mental logic. Mahwah: Lawrence Erlbaum Associates, 1998c. p. 45-61.

- et al. Further evidence for the theory: predicting intermediate and multiple conclusions in propositional logic inference problems. In: BRAINE, Martin D. S.; O’BRIEN, David P. Mental logic. Mahwah: Lawrence Erlbaum Associates, 1998. p. 145197.

BYRNE, R. M. J.; JOHNSON-LAIRD, P. N. 'If' and the problems of conditional reasoning. Trends in Cognitive Science, v. 13, n. 7, p. 282-287, 2009.

DEMORGAN, A. Formal logic: or, the calculus of inference necessary and probable. London: Taylor \& Walton, 1847.

FILLENBAUM, S. Mind your p's and q's: the role of content and context in some uses of and, or, and if. In: BOWER, G. H. (Ed.). The Psychology of learning and motivation. New York: Academic Press, 1977. V. 2. p. 41-100. 
GENTZEN, G. Untersuchungen über das logische, I. Mathematische Zeitschrift, v. 39, n. 2, p. 176-210, 1934.

HANDLEY, S. J.; EVANS, J. St. B. T.; THOMPSON, V. A. The negated conditional: a litmus test for the suppositional conditional? Journal of Experimental Psychology: Learning, Memory and Cognition, v. 32, n.3, p. 559-569, 2006.

JOHNSON-LAIRD, P. N. Against logical form. Psychologica Belgica, v. 5, n. 3/4, p. 193$221,2010$.

. Inference with mental models. The Oxford handbook of thinking and reasoning. New York: Oxford University Press, 2012. p. 134-145.

.; BYRNE, R. M. J.; GIROTTO, V. The mental models theory of conditionals: a reply to Guy Politzer. Topoi, v. 28, n. 1, p. 78-80, 2009.

KHEMLANI, S.; JOHNSON-LAIRD, P. N. Disjunctive illusory inferences and how to eliminate them. Memory \& Cognition, v. 37, n. 5, p. 615-623, 2009.

KHEMLANI, S.; ORENES, I.; JOHNSON-LAIRD, P. N. Negation: a theory of its meaning, representation, and use. Journal of Cognitive Psychology, v. 24, n. 5, p. 541-559, 2012.

.; ___ The negations of conjunctions, conditionals, and disjunctions. Acta Psychologica, v. 151, p. 1-7, Sep. 2014.

LÓPEZ-ASTORGA, M. The mental logic theory and DeMorgan's laws. International Journal of Humanities and Social Science, v. 4, n. 11-1, p. 24-28, 2014.

MACBETH, G. et al. Mental models for the negation of conjunctions and disjunctions. Europe's Journal of Psychology, v. 10, n. 1, p. 135-149, 2014.

O'BRIEN, D. P. Human reasoning includes a mental logic. Behavioral and Brain Sciences, v. 32, n.1, p. 96-97, 2009.

. ; MANFRINATI, A. The mental logic theory of conditional proposition. In: OAKSFORD, M. ; CHATER, N. (Ed.). Cognition and conditionals: probability and logic in human thinking. Oxford: Oxford University Press, 2010. p. 39-54

ORENES, I.; JOHNSON-LAIRD, P. N. Logic, models, and paradoxical inferences. Mind \& Language, v. 27, n. 4, p. 357-377, 2012.

O'TOOLE, R. R.; JENNINGS, R.E. The megarians and the stoics. In: GABBAY, D. M. ; WOODS, J. Handbook of the history of logic: Greek, Indian and Arabic Logic. Amsterdam: Elsevier, 2004. V 1. p. 397-522.

RIPS, L. J. The psychology of proof: deductive reasoning in human thinking. Cambridge: Massachusetts Institute of Technology (MIT) Press, 1994.

Recebido em O9/11/2015

Aceito em 03/12/2015 